\title{
Confirmation of genetic linkage between atopic IgE responses and chromosome 11q13
}

\author{
R P Young, P A Sharp, J R Lynch, J A Faux, G M Lathrop, W O C M Cookson, \\ $\mathrm{J}$ M Hopkin
}

\begin{abstract}
Genetic linkage between atopic IgE responses and chromosome 11 q13 (D11S97) has been previously reported in a limited number of extended families. Difficulties of phenotyping in the older family members, poor family structure in some families, and genetic heterogeneity were proposed as possible explanations for the variability in lod scores. To test this finding a second linkage study of 64 young nuclear families was undertaken and gave a two point lod score of 3.8 at $\theta=0.07$ (assuming $\theta \mathrm{m}=\theta \mathrm{f}$ ). A test of genetic heterogeneity in the nuclear families shows that atopic IgE responses are linked to this locus in 60 to $100 \%$ of families (approximate $95 \%$ confidence limits).
\end{abstract}

Atopy is an allergic disorder that affects over $30 \%$ of some western populations ${ }^{12}$ and is the major (but not exclusive) cause of asthma, rhinitis, and eczema in children and young adults. ${ }^{3}$ Atopy is characterised by immunoglobulin $\mathrm{E}$ ( $\mathrm{IgE}$ ) responses to environmental proteins which are otherwise innocuous and predominantly found in house dust and plant pollens. ${ }^{4}$ Previous investigators have used clinical manifestations or raised total $\mathrm{IgE}$ or both as phenotype markers in genetic studies of atopy but have failed to agree on a consistent mode of inheritance. ${ }^{5-8}$ We have objectively assigned atopic IgE responsiveness (termed IGER and synonomous with atopy in this paper) to family members with either positive skin prick tests, raised specific IgE titres, or raised total IgE titre. ${ }^{910}$ We have used well established normal limits for these tests which have been determined by several population studies. ${ }^{11-13}$

Using these criteria we have described a dominant mode of inheritance of this immunological phenotype (IGER) although other factors, both genetic and environmental, are likely to influence the development of the clinical manifestations of atopy. ${ }^{91415}$ Using this model, genetic linkage in seven extended families was found between $I G E R$ and a polymorphic marker ( $\lambda$ MS.51) on chromosome $11 \mathrm{q} 13$ (lod score $=5 \cdot 6) .{ }^{10}$ Lod score variation between families was attributed, in part, to the effects of age and smoking on reliably identifying the IGER phenotype. As a result, the possibility of genetic heterogeneity (more than one locus independently conferring disease phenotype) could not be resolved. We report the results of two point linkage and heterogeneity analysis in a large sample of atopic nuclear families suggesting the $11 \mathrm{q} 13$ region contains a major locus conferring atopic IgE responsiveness in these families.

\section{Materials and methods}

ASCERTAINMENT AND PHENOTYPING OF FAMILY MEMBERS

Families were recruited in which one or more children under 15 years of age reported symptoms consistent with eczema, asthma, or hayfever, from an allergy clinic $(n=18)$, asthma clinic $(n=18)$, and after responses from a media appeal $(n=28)$. IGER phenotype was assigned, as previously described, ${ }^{10}$ to those with one or more of (1) a skin prick wheal of $2 \mathrm{~mm}$ or more than control to any one of a panel of common environmental antigens (Dome/Hollister-Steir, Spokane, Washington, USA), (2) a specific IgE RAST score of greater than $0.35 \mathrm{PRU} / \mathrm{ml}$ using solid phase immunoassay ('Phadezyme RAST', Pharmacia, Milton Keynes, UK) to the same antigens, or (3) a raised total serum IgE ('Phadezyme IgE PRIST', Pharmacia) corrected for age $(>100 \mathrm{kU} / 1$ for persons over 10 years of age $^{1213}$ and children under 10 years as recommended ${ }^{16}$ ). Parents responded to a questionnaire modified from the American Thoracic Society respiratory questionnaire regarding lifetime symptoms suggestive of asthma, rhinitis, and eczema pertaining to themselves and their children. Phenotype status was assigned without previous knowledge of genotypes by two investigators independently.

DNA METHODS

Genomic DNA was extracted from whole blood and digested with $T a q \mathrm{I}$, separated by gel electrophoresis in $0.8 \%$ agarose and $1 \times \mathrm{TAE}$ buffer, and transferred to nylon filters (Hybond $\mathrm{N}+$, Amersham) by Southern blotting. The pגMS.51 probe (D11S97) was labelled by random hexanucleotide labelling (Amersham), hybridised with the transferred DNA overnight, and washed as previously described. ${ }^{10}$

LINKAGE AND HETEROGENEITY ANALYSIS

Two point linkage analysis was computed by the LINKAGE group of programs (version $5 \cdot 0$ ) using a one liability class model for phenotyping, assuming a gene frequency for atopy of 0.2 and $95 \%$ penetrance. ${ }^{910} \mathrm{~A}$ gene frequency of 0.2 is assumed to be consistent with a dominant disease affecting at least $30 \%$ of the
Received 13 September 1991 Revised version accepted 4 October 1991.

Nuffield Department
of Clinical Medicine,
John Radcliffe
Hospital, Oxford
OX3 9DU.
R P Young
P A Sharp
J R Lynch
W O C M Cookson
Department of
Clinical Immunology,
Churchill Hospital,
Oxford OX3 7LJ.
J A Faux
Centre d'Etude du
Polymorphisme
Humain (CEPH),
27 rue Juliette Dodu,
Paris, France.
G M Lathrop
Osler Chest Unit,
Churchill Hospital,
Oxford OX3 7LJ.
J M Hopkin
Correspondence to
Dr Young, Asthma Genetics
Group, Level 7, Nuffield
Department of Clinical
Medicine, John Radcliffe
Hospital, Headington,
Oxford OX3 9DU.
Received 13 September 1991.
Revised version accepted
4 October 1991.


population with high penetrance. A penetrance of $95 \%$ is based on both previous studies of atopic families and from maximum likelihood estimation from previous data. The presence of genetic heterogeneity was tested by determining $\alpha$, the proportion of families in which atopy is linked to $11 \mathrm{q}$. This was done by maximising the lod score over different values of $\theta$ and $\alpha$, under the hypothesis that atopy and the MS.51 locus show no linkage in a proportion $(1-\alpha)$ of families. ${ }^{17}$ The approximate $95 \%$ confidence limits for $\alpha$ were defined by subtracting one from the maximum lod score.

\section{Results}

\section{PHENOTYPING}

All families in which complete data on both parents and at least two children were obtained were used for study (63 Caucasian and one West Indian). Children's ages ranged from 1 to 18 years (mean age 8.0 years) with 65 girls and 88 boys. In 43 families one parent was atopic, in 16 both parents were atopic, and in five neither parent was demonstrably atopic. Of the designated atopic subjects $(56 \%$ of the parents and $75 \%$ of children), $91 \%$ of parents and $74 \%$ of children were positive for skin prick testing or RAST or both, $77 \%$ of parents and $63 \%$ of children were positive for two or more criteria, $80 \%$ of parents and $78 \%$ of children reported symptoms, and $1 \%$ of parents and $4 \%$ of children were positive on skin testing only. Of the $79 \%$ of atopic subjects with symptoms during their life, $57 \%$ had asthma, $56 \%$ had rhinitis, and $39 \%$ had eczema.

\section{TWO POINT LINKAGE ANALYSIS}

The maximum lod score was 3.80 at $\theta=0.067$ (under the assumption $\theta$ male $=\theta$ female) from 32 informative families giving 46 meioses. However, a test of male/female difference in $\theta$ is significant with estimated $\theta \mathrm{m}=0 \cdot 182$ and $\theta f=0.001 \quad\left(\chi^{2}=6.44,1 \mathrm{df}, \mathrm{p}<0.02\right)$; the test statistic for linkage under this hypothesis is 5.21 on the lod scale. The contributions from the families in which one, both, or neither parents were atopic were $+3.59,+0.62$, and +1.00 respectively. The results were not sensitive to changes in penetrances: the maximum lod statistic was 5.50 if penetrance was assumed to be $99 \%$ and 4.87 if it was assumed to be $90 \%$.

\section{HETEROGENEITY ANALYSIS}

Using the two point data between atopy and $\lambda$ MS.51 in the nuclear families, under the assumption of equal male and female recombination frequencies, the maximum likelihood estimate of the proportion of linked families was $\alpha=1.0$ (no heterogeneity). The approximate $95 \%$ confidence region based on a $\chi^{2}$ distribution with one degree of freedom extends to $\alpha=0.6$ (that is, in 60 to $100 \%$ of families atopic IgE responsiveness appears to be linked to the $11 \mathrm{q}$ locus).

\section{Discussion}

Our results support the hypothesis that atopic IgE responsiveness (IGER) is linked to chromosome 11 q13 (combined lod score in nuclear and extended families is in excess of 8). The testing of further families in the presence of incorrect assignment of phenotype, significant genetic heterogeneity, or phenocopies would have reduced rather than added to the lod score ${ }^{18}$ In the present study of young families, phenotyping of atopy was considerably easier because the effects of smoking and old age were reduced. Of the designated atopic subjects, $74 \%$ of children and $91 \%$ of parents were positive for skin prick testing or RAST or both. A high total IgE was the sole criterion in $9 \%$ of parents and $26 \%$ of children, a high $\operatorname{IgE}$ being highly predictive for the development of atopic disorders (asthma, rhinitis, and eczema) in children. ${ }^{19}$ All parents were under the age of 52 years (mean 37.0 years, range 24 to 52 ) and all of the $9 \%$ of parents with a raised total IgE as their only criterion were non-smokers. Positive skin testing was the sole criterion in only $4 \%$ of the children and in only $1 \%$ of the parents.

In both the nuclear and extended family studies we have consistently found 5 to $10 \%$ of atopic subjects have apparently non-atopic parents. This could be the result of phenocopies, incomplete penetrance, or genetic heterogeneity. In the five nuclear families from this study in which neither parent was affected $(8 \%$ of nuclear families), the lod score contribution was 1.0 (of the total score of 5.2), which supports our model and suggests that a nonpenetrant heterozygote parent may be present in each of these families. The estimated difference in the male/female recombination frequencies is the subject of further analysis.

Though the precise assignment of individual nuclear families with small sibships to an unlinked group has limitations, the heterogeneity analysis has allowed us to define the proportion of families linked to $11 \mathrm{q}$ within confidence limits. The $95 \%$ confidence interval for $\alpha$ was 60 to $100 \%$ in the nuclear families we recruited. We believe the recruitment of more families is necessary to test further for heterogeneity of this immunological phenotype at this locus. However, confirmation of linkage in this study of a larger sample of the atopic population, together with our heterogeneity analysis, suggests the $11 \mathrm{q} 13$ region contains a major locus conferring atopic IgE responsiveness, the underlying immunological abnormality that characterises the common allergic disorders of atopy.

We are happy to provide interested investigators with the phenotype and genotype data from this study. We thank ICI Ltd for the pMS.51 probe, the British Council for their support of RPY, the Wellcome Trust for their support of WOCMC and JMH, and the National Asthma Campaign and the Wellcome Trust for their support of this study. 1 Holford-Strevens V, Warren P, Wong C, Manfreda J. Allergy Clin Immunol 1984;73:516-22. 
2 Peat JK, Britton WJ, Salome CM, Woolcock AJ. Bronchial hyperresponsiveness in two populations of Australian schoolchildren. II. The relative importance of associated factors. Clin Allergy 1987;17:283-90.

3 Price JF. Paediatric allergy. In: Lessof $\mathrm{MH}$, Lee $\mathrm{TH}$ Kemeny DM, eds. Allergy: an international textbook. Chichester: John Wiley and Sons, 1987:423-53.

4 Pepys J. Atopy. In: Gell PGH, Coombs RRA, Lachmann PJ, eds. Clinical aspects of immunology. Oxford: Blackwell Scientific Publications, 1975:877-902.

5 Marsh DG, Bias WB, Ishizaka K. Genetic control of basal serum immunoglobulin $E$ levels and its effects on specific reaginic sensitivity. Proc Natl Acad Sci USA 1974;71:3588-92.

6 Gerrard JW, Rao DC, Morten NE. A genetic study of immunoglobulin E. Am f Hum Genet 1978;30:46-58.

7 Blumenthal MN, Naboodiri K, Mendell N, Gleich G, Elston RC, Yunis E. Genetic transmission of IgE levels. Am f Med Genet 1981;10:219-28.

8 Borecki IB, Rao DC, Lalouel JM, Mcgue L, Gerrard JW. Demonstration of a common major gene with pleiotropic effects on immunoglobulin E levels and allergy. Genet Epidemiol 1985;2:327-38.

9 Cookson WOCM, Hopkin JM. Dominant inheritance of atopic IgE responsiveness. Lancet 1988; i:86-8.

10 Cookson WOCM, Sharp PA, Faux JA, Hopkin JM. Linkage between immunoglobulin $\mathrm{E}$ responses underlying age between immunoglobulin $E$ responses underlying asthma and 1989 ;: $1292-5$.
11 Marsh DG, Bias W, Ishizaka K. Genetic control of basal serum immunoglobulin E level and its effects on specific
reaginic sensitivity. Proc Natl Acad Sci USA reaginic sensitivity.
1974;71:3588-92.

12 Zetterstrom O, Johansson SGO. IgE concentrations measured by PRIST in serum of healthy adults and in

patients with respiratory allergy. Allergy 1981;36:537-47.
13 Wittig HJ, Belliot J, De Fillipi I, Royal GJ. Age-related ittig HJ, Belliot J, De Fillipi 1, Royal GJ. Age-related serum immunoglobulin E levels in healthy subjects and in patients with allergic disease. F Allergy Clin Immunol
1980;66:305-13. 4 Marsh DG, Zwollo P, Huang SK, Ansari AA. Molecular genetics of human immune responsiveness to allergens.
In: IgE, mast cells and the allergic response. Chichester: John Wiley and Sons, 1989:171-87.

15 Sears MR, Herbison GP, Holdaway MD, et al. The relative risks of sensitivity to grass pollen, house dust mite and cat dander in the development of childhood asthma. Clin Exp Allergy 1989;19:419-24.

16 Kjellman N-IM, Johansson SJO, Roth A. Serum IgE levels in healthy children quantified by a sandwich technique (PRIST) Clin Allergy 1976;6:51-9.

17 Smith CAB. Testing for heterogeneity of recombination fraction values in human genetics. Ann Hum Genet raction values

18 Gurling $\mathrm{H}$. Genetic linkage and psychiatric disease. Nature 1990;344:298.

19 Kjellman N-IM. Predictive value of high IgE levels in children. Acta Paediatr Scand 1976;65:465-71. 